\title{
Chinese Expert Consensus on Ultrasonographic Acquisition, Measurement, and Reporting System for Developmental Dysplasia of the Hip
}

\author{
Writing Group of the Pediatric Ultrasound Committee of Ultrasound Branch of Chinese Medical Education Association \\ Na Xu, MD ${ }^{a}$, Bei Xia, MD ${ }^{a, *}$, Hongwei Tao, MD ${ }^{a}$, Ke Sun, MD ${ }^{b}$, Qinghua Liu, MD ${ }^{c}$, Wenjuan Chen, MD ${ }^{d}$, Dan \\ Wang, MD ${ }^{e}$, Hong Gao, MD ${ }^{f}$, Yan Guo, MD ${ }^{g}$, Yan Liu, MD ${ }^{h}$, Jun Gao, MD ${ }^{i}$, Jianbo Teng, MD ${ }^{j}$ \\ ${ }^{a}$ Department of Ultrasound, The Shenzhen Children's Hospital, China $;{ }^{b}$ Department of Orthopedics, The Shenzhen Children's Hospital, \\ China; ${ }^{c}$ Department of Ultrasound, The Qilu Children's Hospital of Shandong University, China; ${ }^{d}$ Department of Ultrasound, The \\ Hunan Children's Hospital, China; ${ }^{e}$ Department of Ultrasound, The Henan Children's Hospital, China, ${ }^{f}$ Department of Ultrasound, The \\ Kunming Children's Hospital, China; ${ }^{g}$ Department of Ultrasound, The Shanxi Children's Hospital, China; ${ }^{h}$ Department of Ultrasound, \\ The Guizhou Women and Children's Hospital, China; ${ }^{i}$ Department of Ultrasound, The Wuhan Women's and Children's Health Care \\ Center (Wuhan Children's Hospital), China; ${ }^{j}$ Shandong Medical Imaging Research Institute, China
} Received December 16, 2019; revision received January 07, 2020; accepted January 14, 2020.

\section{Introduction}

\section{Purpose}

Developmental dysplasia of the hip (DDH) is one of the most common skeletal dysplasias in infants. There are significant differences in incidence among different ethnic and regions, ranging from $0.15 \%$ to $2 \%$ [ [1], with etiology related to congenital hereditary factors and postnatal factors [2]. Early diagnosis and treatment during childhood can prevent DDH from developing and result in completely normal hip joint structure and function in affected children. Delayed diagnosis and treatment can lead to different degrees of joint deformity, even disability. DDH is currently the most common cause of hip replacement in patients under 60 years of age. A large number of late- diagnosis cases [3] not only bring various difficulties to the treatment, but also cause great difficulties to the preservation of hip function after treatment. Therefore, the early diagnosis and treatment of DDH is very important.

\section{Source and Selection Criteria}

Publications from January 2000 to January 2019 were searched through PubMed, and a combination of the following medical subject headings (MeSH) were used for the searches: (dysplasia of the hip) AND (ultrasound or ultrasonography or hyperacoustic or ultrasonic). References were validated and articles with high impact factors were selected first. The search identified many research reports on DDH [4-21] and evidence-based guidelines and paper on DDH ultrasound in North America and Europe [22-26]. Considering that incidence, examination methods, and diagnostic criteria for DDH may be influenced by race, region, age, habits, and that differences in health care systems, we determined that it is necessary to unify the Chinese methods of DDH ultrasound examination and establish a uniform set of methods. This set of methods could be applied to different regions, different medical center, used for the screening, inspection and re-examination of hip joint, and to provide the basis for how to prevent, diagnose and treat DDH research.

\footnotetext{
* Corresponding author: Bei Xia Department of Ultrasonography, Shenzhen Children's Hospital, 7019, Yitian Road, Shenzhen, Guangdong, China

e-mail:xiabeimd@qq.com

2576-2508/O AUDT $2020 \cdot \mathrm{http}: / / w w w . A U D T . o r g$

This is an open-access article distributed under the terms of the Creative Commons Attribution 4.0 International license, which permits unrestricted use, distribution and reproduction in any medium provided that the original work is properly attributed.
} 


\section{Preparation}

In 2014, Professor Bei Xia from the Department of Ultrasound, Shenzhen Children's Hospital engaged experts in DDH ultrasound in China to set up the National DDH Ultrasound Examination Cooperative Group. At the meeting, the preliminary idea of formulating the China's children's DDH ultrasound examination standard was mentioned. DDH multicenter research emerged in 2016 (China Clinical Trial Center Registration No. ChiCTR-ODC-16008748, Ethics Committee approved No. 2016 [002]). Subsequently, many DDH multi-center satellite conferences were held. The cooperative units combined to examine the relevant international and Chinese consensus guidelines, and, after repeated discussions, formed this expert consensus. This consensus document will continue to be improved according to feedback in the future. It uses the following grading system for the level of evidence for each recommendation (Table 1).

Table 1 Evidence level and recommendation strength

A Highly recommended. Evidence-based evidence $<<$ is strong and $>>$ certainly improves prognosis and does more good than harm.

B Recommended. Evidence-based evidence is good, improves prognosis, and does more good than harm.

C Recommended. Based on expert advice.

D Against recommendation. Based on expert advice.

E Against recommendation. Evidence-based evidence is good and does not improve or harm the prognosis.

F Strongly against recommendation. Evidence-based evidence affirms that it does not improve prognosis or does more harm than good to it.

G Not recommended or as a regular recommendation. It is impossible to evaluate the pros and cons of the lack of evidence, lack of evidence, or conflicting results.

\section{Indications/Contraindications and Timing}

Ultrasound can be used to monitor DDH screening, diagnosis, and treatment. Indications of ultrasonography include the following [22]:

1. Abnormal physical examination of the hip joint.

2. DDH family history.

3. Breech presentation, torticollis, oligohydramnios.

4. Detection of DDH treatment.

5. Physical examination of infants.

6. Except for pathological dislocation, paralytic dislocation, spastic dislocation of the hip joint, teratoid dislocation, and other conditions.

Due to the presence of physiologic laxity, hip sonography is not performed on patients younger than 2 weeks of age unless clinical findings indicate dislocation or significant instability. For children over 6 months old, the study becomes less reliable compared to radiography because ossification of the femoral head progresses, and ultrasound examination can be selected according to clinical requirements.

Recommendations: Follow the guidelines from the ACR Appropriateness Criteria ${ }^{\circledR}$ on Developmental Dysplasia of the Hip-Child [27], and the American Academy of Orthopedic Surgeons Evidence-Based Guideline on Detection and Nonoperative Management of Pediatric Developmental Dysplasia of the Hip in Infants up to Six Months of Age [28]. Recommended level: A.

\section{Equipment}

Hip ultrasound for detecting DDH should be performed with a higher frequency linear probe and depth to meet the necessary penetration. The instrument may have preconditions for DDH ultrasonic examination. Total ultrasound exposure should be kept as low as reasonably achievable while optimizing diagnostic information.

The examination bed is a commonly used as the diagnostic bed.

\section{Qualifications and Responsibilities of Personnel}

1. Master the basic knowledge and skills of DDH ultrasonic examination.

1.1 Identify the anatomy of the hip correctly by ultrasound: ilium, pubis, ischium, ossified margin of the ilium, labrum, articular capsule, plica synovialis, femoral head, greater trochanter, and ossified end of the femur (Fig. 1).

1.2 Take the measurements with hip ultrasound mainly include alpha angle, femoral head coverage, femoral head size, pubis-femoral distance, ischiumfemoral distance, and femoral-pubis distance.

1.3 Master the manipulation and criteria of the hip stability test (body axial, adduction and abduction).

2. For hospitals that have not yet carried out DDH ultrasound examination, the physicians need to receive standardized hospital training on the operation and diagnostic capacity for DDH ultrasound.

2.1 Operational training: under the guidance of professional DDH ultrasound doctors, trainees should complete 50 cases of DDH ultrasonography and including more than $10 \%$ abnormal cases.

2.2 Diagnostic ability training: under the guidance of professional DDH ultrasound doctors, trainees should independently diagnose 50 cases of DDH. The coincidence rate of the main diagnosis should be more than $90 \%$ and including more than $10 \%$ abnormal cases. 

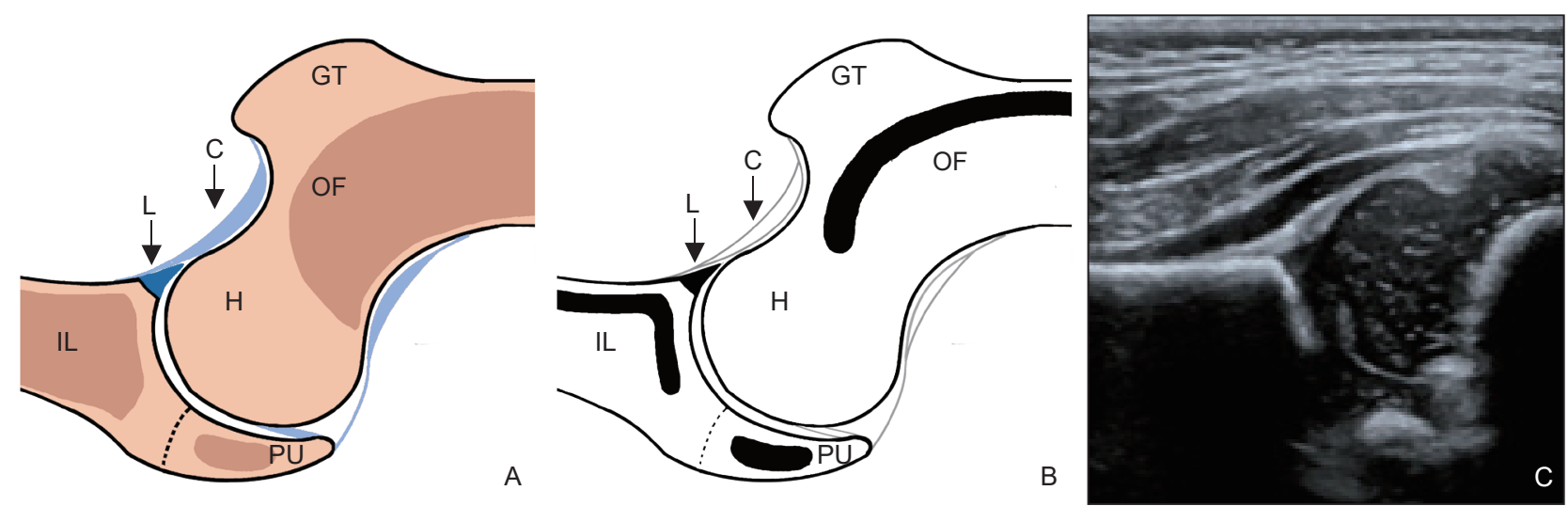

Figure 1 Identify the anatomy of hip ultrasound. (A) Hip anatomy schematic diagram; (B) Coronary section of the corresponding hip ossification: (C) Coronal section image of infant hip. IL, ilium; PU, pubis; H, femoral head; GT, greater trochanter; OF, Ossified end of femur; C, joint capsule; L, labrum.

\section{Specifications of the Examination}

\section{The body position}

It is acceptable to perform the examination with the infant in a supine or a lateral decubitus position. Morphology is assessed at rest or with the lower extremities relaxed.

Neutral position: The hip is neutral and the knee is at shoulder width on the same side (Fig. 2A, 2B).

Flexion position: The hip flexion is $90^{\circ}$ and the knee is at shoulder-width on the same side (Fig. 2C, 2D).

The doctor is located on the right side of the patient, and the parents are located on the left side of the patient to assist the child into position and to comfort the child so that the child can keep as quiet and relaxed as possible.

Recommendations: Follow the guidelines of the AIUM-ACR-SPR-SRU practice parameter for the performance of an ultrasound examination for detection and assessment of developmental dysplasia of the hip [24]. Recommended level: A.

\section{Specifications of the Examination}

Bilateral hips should be examined. The purpose of DDH ultrasound is to evaluate hip stability, the femoral head position and the acetabular morphology. Referring to the clinical practice guidelines from the American Institute of Ultrasound in Medicine (AIUM), the American College of Radiology (ACR), the Society for Pediatric Radiology (SPR), and the Society of Radiologists in Ultrasound (SRU) [22-25], this standard is formulated jointly according to the relevant guidelines at home and abroad and the experience of multi-center research in China [29].

All the children were examined in two standard positions neutral and flexion hip position, and image storing and quantitative analysis. Four static diagrams and four (loop) dynamic diagrams are required for each hip sides (Fig. 2). The recommendations for specifications of the operation are shown in Table 2.

\section{Specifications of the Measurement}

The following measurements were performed on a standardized hip section (Fig. 3): alpha angle, femoral head coverage (FHC), femoral head size, pubo-femoral distance, ischium-femoral distance, and femoral-pubo distance.

\section{In order to improve the accuracy of measurement, all data are measured on the machine.}

1. $\alpha$ angle measurement: As shown in Figure 3A, this angle should be measured in neutral position or flexion position with coronal section imaging.

2. $\beta$ angle measurement: As shown in Figure 3B, this angle should be measured in neutral position with coronal section imaging.

3. FHC measurement: As shown in Figure 3C, this parameter should be measured in neutral position or flexion position with coronal section imaging.

4. Femoral head size measurement: As shown in Figure 3D, this parameter should be measured in neutral position with coronal section imaging.

5. PFD and IFD measurements: As shown in Figure $3 \mathrm{E}$, this parameter should be measured in neutral position with transverse section imaging.

6. FPD measurement: As shown in Figure 3F, this parameter should be measured in flexion position with transverse section imaging.

\section{Recommendations:}

1. $\alpha$ angle measurement refers to Grafe's method [30,31]. Recommended level: A.

2. $\beta$ angle measurement refers to improved Grafe's method and "Ultrasonic quantitative analysis of the 

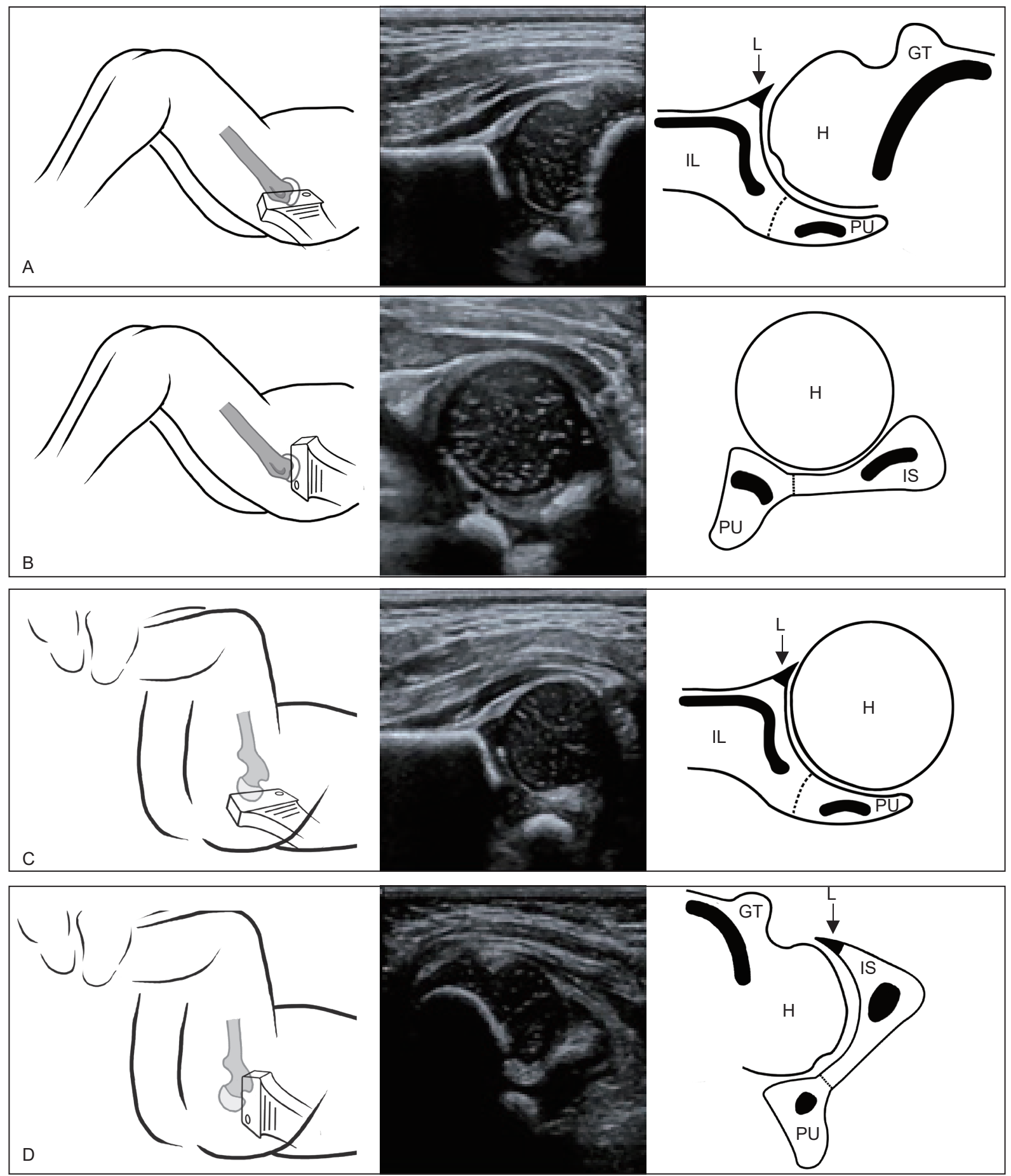

Figure 2 Hip ultrasound of the body position, standard image and anatomic illustration.

(A) Neutral posture hip coronal image; (B) Neutral posture hip transverse image; (C) Flexion posture coronal image; (D) Flexion posture hip transverse image. IL, ilium; PU, pubis; IS, ischium; H, femoral head; GT, greater trochanter; L, labrum.

flexion cornal hip in the normal infant." [30-32]. Recommended level: $\mathrm{C}$.

3. FHC measurements refer to Terjesen's method [10, 11]. Recommended level: A.

4. Femoral head measurement refers to the "Developmental dislocation of the hip in infants: the hip's ultrasound quantitative analysis" study [33]. Recommended level: B.

5. PFD and IFD measurements refer to "Ultrasonic measurement and analysis of hip in healthy infants: a multicenter study" [29]. Recommended level: B.

6. FPD measurement refers to the "Comparison 
Table 2 Specifications of the hip ultrasound operation

\begin{tabular}{|c|c|c|c|c|c|c|}
\hline Number & Body position & Section or view & $\begin{array}{l}\text { Content of } \\
\text { measurement }\end{array}$ & $\begin{array}{l}\text { Meaning of } \\
\text { expression }\end{array}$ & Normal reference data & $\begin{array}{l}\text { Recommended } \\
\text { level }\end{array}$ \\
\hline 1 & Neutral position & $\begin{array}{l}\text { Coronal section } \\
\quad \text { (Fig. 2A) }\end{array}$ & $\begin{array}{c}\alpha \text { angle (Fig. 3A), } \\
\beta \text { angle (Fig. 3B), } \\
\text { femoral head coverage } \\
\text { (FHC) (Fig. 3C), length } \\
\text { (L) and width (W) of } \\
\text { femoral head (Fig. 3D) }\end{array}$ & $\begin{array}{l}\text { The ossified } \\
\text { acetabular } \\
\text { morphology, the } \\
\text { position of the } \\
\text { femoral head }\end{array}$ & $\begin{array}{l}\text { 1. Graf R. (1980, 2017, 2006) }[9,30,31] \\
\text { 2. AIUM-ACR-SPR-SRU. (2018) [24] } \\
\text { 3. Terjesen et al. (1989,1989) }[10,11] \\
\text { 4. Huang et al. (2018) [29] } \\
\text { 5. Miao et al. (2017) [32] }\end{array}$ & A \\
\hline 2 & Neutral position & $\begin{array}{l}\text { Dynamic coronal } \\
\text { view }\end{array}$ & - & $\begin{array}{l}\text { The lower edge } \\
\text { point of the } \\
\text { ossified ilium }\end{array}$ & 1. Tao et al. (2017) [33] & $\mathrm{C}$ \\
\hline 3 & Neutral position & $\begin{array}{l}\text { Transverse section } \\
\text { (Fig. 2B) }\end{array}$ & $\begin{array}{l}\text { Pubo-femoral distance } \\
\text { (PFD), ischium-femoral } \\
\text { distance (IFD) } \\
\text { (Fig. 3E) }\end{array}$ & $\begin{array}{l}\text { The degree } \\
\text { of lateral and } \\
\text { posterior; } \\
\text { Displacement of } \\
\text { the femoral head }\end{array}$ & 1. Harcke et al. (1990) [13] & $\mathrm{B}$ \\
\hline 4 & Neutral position & $\begin{array}{l}\text { Axial stability test } \\
\quad \text { (Fig. 4A) }\end{array}$ & - & $\begin{array}{c}\text { Yes or no of the } \\
\text { displaced femur } \\
\text { head }\end{array}$ & 1. Graf R. $(2017,2006)[30,31]$ & B \\
\hline 5 & Flexion position & $\begin{array}{l}\text { Coronal section } \\
\text { (Fig. 2C) }\end{array}$ & $\begin{array}{l}\alpha \text { angle, femoral head } \\
\text { coverage (FHC) }\end{array}$ & $\begin{array}{l}\text { The ossified } \\
\text { acetabular } \\
\text { morphology; } \\
\text { The femoral } \\
\text { head position }\end{array}$ & 1. AIUM-ACR-SPR-SRU. (2018) [24] & A \\
\hline 6 & Flexion position & $\begin{array}{l}\text { Transverse section } \\
\text { (Fig. 2D) }\end{array}$ & $\begin{array}{l}\text { Femoral-pubo distance } \\
\text { (FPD) (Fig3F) }\end{array}$ & $\begin{array}{l}\text { Quantitative } \\
\text { assessment of } \\
\text { the instability }\end{array}$ & $\begin{array}{l}\text { 1. Harcke et al. (1984, 1990,1995) [12-14] } \\
\text { 2. AIUM-ACR-SPR-SRU. (2018) [24] }\end{array}$ & A \\
\hline 7 & Flexion position & $\begin{array}{l}\text { Adduction } \\
\text { stability test } \\
\text { (Fig. 4B) }\end{array}$ & - & $\begin{array}{l}\text { Yes or no of the } \\
\text { hip dislocation }\end{array}$ & $\begin{array}{l}\text { 1. Harcke et al. (1984, 1990,1995) [12-14] } \\
\text { 2. AIUM-ACR-SPR-SRU. (2018) [24] }\end{array}$ & A \\
\hline 8 & Flexion position & $\begin{array}{l}\text { Abduction } \\
\text { stability test } \\
\text { (Fig.4C) }\end{array}$ & - & $\begin{array}{l}\text { Yes or no of the } \\
\text { displaced femur } \\
\text { and be retracted }\end{array}$ & $\begin{array}{l}\text { 1. Harcke et al. }(1984,1990,1995)[12-14] \\
\text { 2. AIUM-ACR-SPR-SRU. (2018) [24] }\end{array}$ & A \\
\hline
\end{tabular}
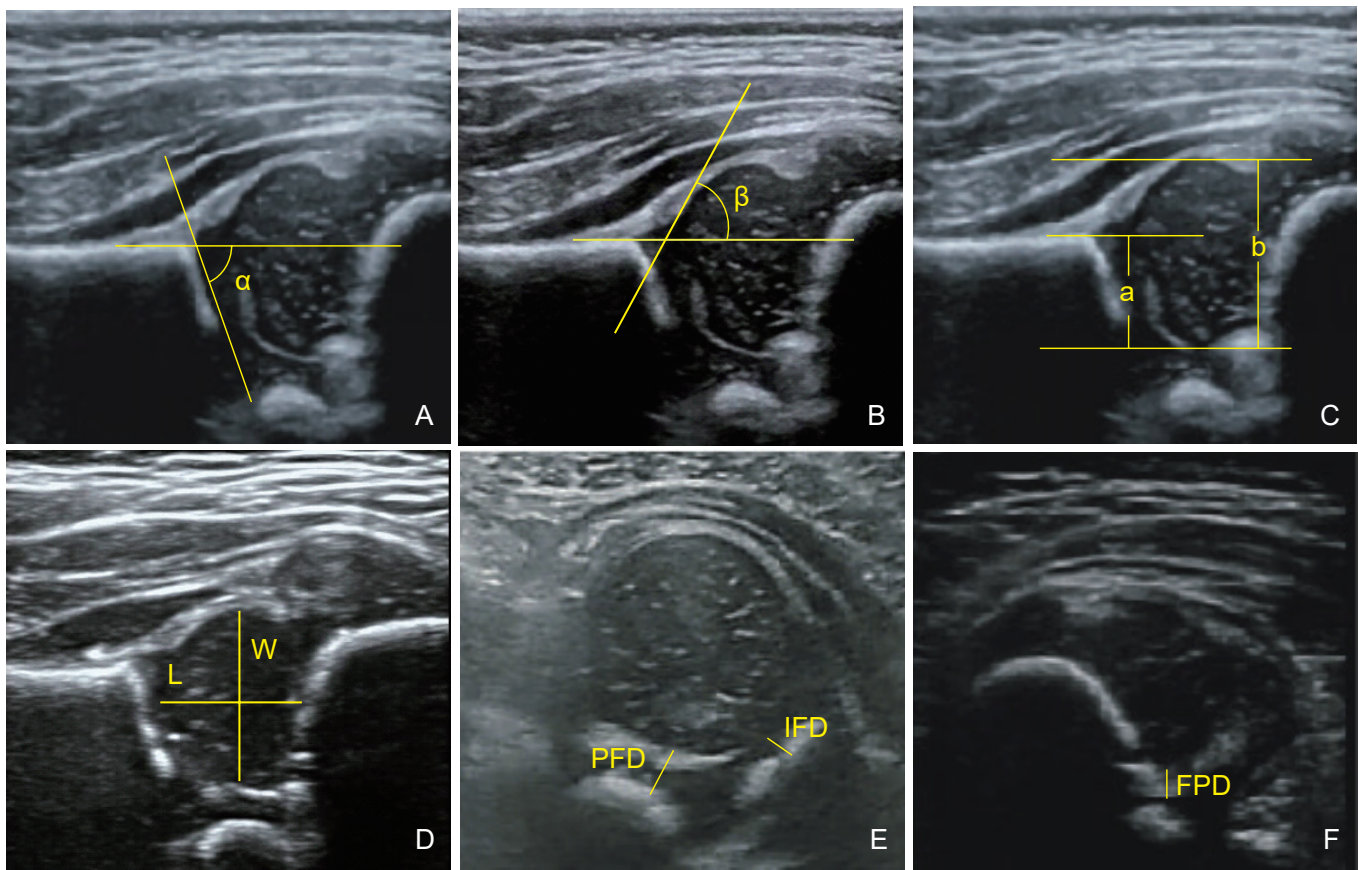

Figure 3 Specifications of the hip ultrasound measurements

(A) Alpha angle; (B) $\beta$ angle; (C) Femoral head coverage ((b-a)/b); (D) Femoral head size, Length (L), Width (W); (E) Pubo-femoral distance (PFD) and ischium-femoral distance (IFD); (F) Femoral-pubo distance (FPD). 


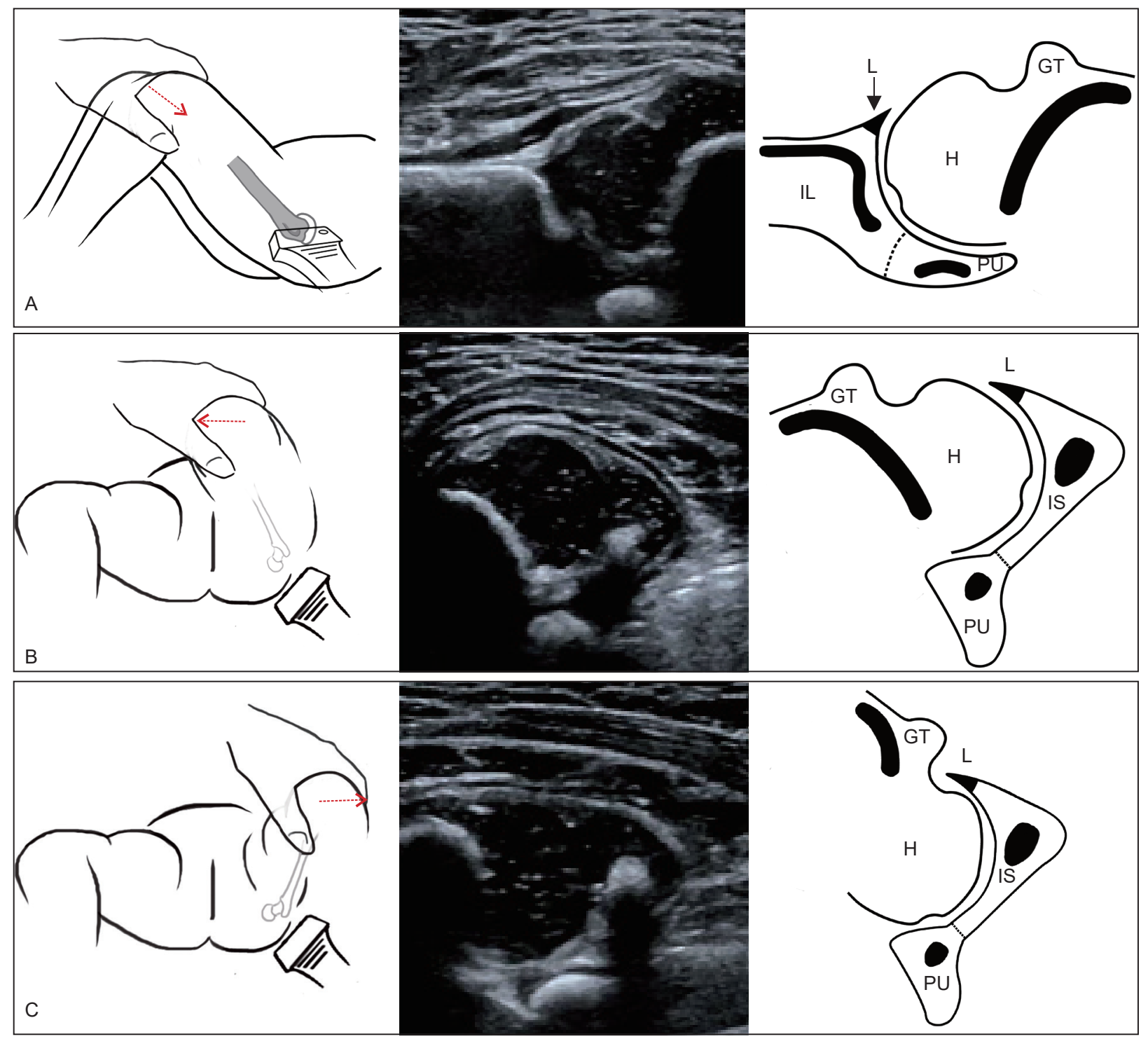

Figure 4 Hip ultrasound of the body position, standard image and anatomic illustration.

(A) Axial stability test; (B) Adduction stability test; (C) Abduction stability test. IL, ilium; PU, pubis; IS, ischium; H, femoral head; GT, greater trochanter; L, labrum.

between Graf method and pubo-femoral distance in neutral and flexion positions to diagnose developmental dysplasia of the hip", and "Pubo-femoral distance: an easy sonographic screening test to avoid late diagnosis of developmental dysplasia of the hip" studies [34,35]. Recommended level: B.

\section{Report}

The acetabular morphology, the femoral head position, the hip stability, and the quantitative analysis results should be described in the report. The ultrasound examination and its interpretation should be available as a permanent record, including all abnormal and normal images. The application of DDH ultrasonography includes Graf's method, Hacker's method, and
Terjesen's method, among others. The examinations and measurement programs mentioned above can be selected according to clinical needs to develop a clinical diagnosis and follow-up the hip treatment.

To observe the development of hip joint, it is suggested that all infants less than 6 months old should be followed up. Follow-up is important for establishing a mechanism to avoid missing any abnormal hip development and prevent dislocation in the early stages of life.

\section{Limitation and Potential Developments}

We need a large study population before and after treatment to meet the clinical needs. And this consensus helps to identify patients with mild hip disease who do 
not need surgery. So as to improve the basis of early treatment for such patients.

\section{Acknowledgments}

The authors thank Shengping Tang and Jinming Han, directors of the Orthopedics Department of Shenzhen Children's Hospital, for their guidance.

The authors thank Zijian Tang for drawing the illustrations.

\section{Conflicts of Interest}

The authors declare no conflict of interests.

\section{Reference}

[1] Peled E, Eidelman M, Katzman A, Bialik V. Neonatal incidence of hip dysplasia: ten years of experience. Clin Orthop Relat Res 2008;466:771-775.

[2] Aronsson DD, Goldberg MJ, Kling TF Jr, Roy DR. Developmental dysplasia of the hip. Pediatrics 1994;94:201-208.

[3] Engesaeter IØ, Lie SA, Lehmann TG, Furnes O, Vollset SE, Engesaeter LB. Neonatal hip instability and risk of total hip replacement in young adulthood: follow-up of 2,218,596 newborns from the Medical Birth Registry of Norway in the Norwegian Arthroplasty Register. Acta Orthop 2008;79:321-326.

[4] D'Alessandro M, Dow K. Investigating the need for routine ultrasound screening to detect developmental dysplasia of the hip in infants born with breech presentation. Paediatr Child Health 2019;24:e88-e93.

[5] Lussier EC, Sun YT, Chen HW, Chang TY, Chang CH. Ultrasound screening for developmental dysplasia of the hip after 4 weeks increases exam accuracy and decreases follow-up visits. Pediatr Neonatol 2019;60:270-277.

[6] Geertsema D, Meinardi JE, Kempink DRJ, Fiocco M, van de Sande MAJ. Screening program for neonates at risk for developmental dysplasia of the hip: comparing first radiographic evaluation at five months with the standard twelve week ultrasound. A prospective cross-sectional cohort study. Int Orthop 2019;43:1933-1938.

[7] Westacott DJ, Butler D, Shears E, Cooke SJ, Gaffey A. Universal versus selective ultrasound screening for developmental dysplasia of the hip: a single-centre retrospective cohort study. J Pediatr Orthop B 2018;27:387-390.

[8] Olsen SF, Blom HC, Rosendahl K. Introducing universal ultrasound screening for developmental dysplasia of the hip doubled the treatment rate. Acta Paediatr 2018;107:255-261.

[9] Graf R. The diagnosis of congenital hip-joint dislocation by the ultrasonic combound treatment. Arch Orthop Trauma Surg 1980;97:117-133.

[10] Terjesen T, Bredland T, Berg V. Ultrasound for hip assessment in the newborn. J Bone Joint Surg Br 1989;71:767-773.

[11] Terjesen T, Rundén TO, Tangerud A. Ultrasonography and radiography of the hip in infants. Acta Orthop Scand 1989;60:651660.

[12] Harcke HT, Clarke NM, Lee MS, Borns PF, MacEwen GD. Examination of the infant hip with real-time ultrasonography. $J$ Ultrasound Med 1984;3:131-137.

[13] Harcke HT, Grissom LE. Performing dynamic sonography of the infant hip. AJR Am J Roentgenol 1990;155:837-844.

[14] Harcke HT, Walter RS. Ultrasound screening for dysplasia of the hip.
Pediatrics 1995;95:799-800.

[15] Morin C, Harcke HT, MacEwen GD. The infant hip: real-time US assessment of acetabular development. Radiology 1985;157:673-677.

[16] Biedermann R, Riccabona J, Giesinger JM, et al. Results of universal ultrasound screening for developmental dysplasia of the hip: a prospective follow-up of 28092 consecutive infants. Bone Joint $J$ 2018;100-B:1399-1404.

[17] Duque Orozco MDP, Abousamra O, Rogers KJ, Thacker MM. Radiographic analysis of the pediatric hip patients with hereditary multiple exostoses (HME). J Pediatr Orthop 2018;38:305-311.

[18] Westacott DJ, Butler D, Shears E, Cooke SJ, Gaffey A. Universal versus selective ultrasound screening for developmental dysplasia of the hip: a single-centre retrospective cohort study. $J$ Pediatr Orthop B 2018;27:387-390.

[19] Lehmann HP, Hinton R, Morello P, Santoli J. Developmental dysplasia of the hip practice guideline: technical report. Committee on quality improvement, and subcommittee on developmental dysplasia of the hip. Pediatrics 2000;105:E57.

[20] Mulpuri K, Song KM, Gross RH, Tebor GB, Otsuka NY, Lubicky JP et al. The american academy of orthopaedic surgeons evidence-based guideline on detection and nonoperative management of pediatric developmental dysplasia of the hip in infants up to six months of age. J Bone Joint Surg Am 2015;97:1717-1718.

[21] Williams D, Protopapa E, Stohr K, Hunter JB, Roposch A. The most relevant diagnostic criteria for developmental dysplasia of the hip: a study of British specialists. BMC Musculoskelet Disord 2016;17:38.

[22] American Institute of Ultrasound in Medicine; American College of Radiology. AIUM practice guideline for the performance of an ultrasound examination for detection and assessment of developmental dysplasia of the hip. J Ultrasound Med 2009;28:114119.

[23] American Institute of Ultrasound in Medicine. AIUM practice guideline for the performance of an ultrasound examination for detection and assessment of developmental dysplasia of the hip. $J$ Ultrasound Med 2013;32:1307-1317.

[24] AIUM-ACR-SPR-SRU. AIUM-ACR-SPR-SRU practice parameter for the performance of an ultrasound examination for detection and assessment of developmental dysplasia of the hip. J Ultrasound Med 2018;37:E1-E5.

[25] Rosendahl K, Toma P. Ultrasound in the diagnosis of developmental dysplasia of the hip in newborns. The European approach. A review of methods, accuracy and clinical validity. Eur Radiol 2007;17:19601967.

[26] Laborie LB, Markestad TJ, Davidsen H, Brurås KR, Aukland SM, Bjørlykke JA, et al. Selective ultrasound screening for developmental hip dysplasia: effect onmanagement and late detected cases. A prospective survey during 1991-2006. Pediatr Radiol 2014;44:41024.

[27] Expert Panel on Pediatric Imaging:, Nguyen JC, Dorfman SR, Rigsby CK, Iyer RS, Alazraki AL, Anupindi SA et al. ACR appropriateness criteria ${ }^{\circledR}$ developmental dysplasia of the hip-child. J Am Coll Radiol 2019;16:S94-S103.

[28] Mulpuri K, Song KM, Gross RH, Tebor GB, Otsuka NY, Lubicky JP, et al. The American Academy of Orthopaedic Surgeons evidencebased guideline on detection and nonoperative management of pediatric developmental dysplasia of the hip in infants up to six months of age. J Bone Joint Surg Am 2015;97:1717-1718.

[29] Huang BX, Xia B, Xu N, Tang HW, He XZ, Yu W, et al. Ultrasonic measurement and analysis of hip in healthy infants: a multicenter study. Chin J Ultrasonogr 2018;27:417-422. [In Chinese] Available from: http://d.old.wanfangdata.com.cn/Periodical/zhcsyx201805010

[30] Graf R. Hip sonography: background; technique and common 
mistakes; results; debate and politics; challenges. Hip Int 2017;27:215-219.

[31] Graf R. Hip Sonography. Springer Berlin Heidelberg; 2006. 196 p. Available from: https://doi.org/10.1007/3-540-30958-6.

[32] Miao LL, Liu QH, Liu XF, Zhang XC, Yan YX, Pang HP. Ultrasonic quantitative analysis of the flexion cornal hip in the normal infant. Chin J Ultrasonogr 2017;26:703-707. [In Chinese] Available from: http://rs.yiigle.com/CN131148201708/1006473.htm

[33] Tao HW, Sun K, Xia B, Shi W, Chen WL, Xu N, et al. Developmental dislocation of the hip in infants: the hip's ultrasound quantitative analysis. Chin J Med Ultrasound (Electronic Edition) 2017;3:210-
219. [In Chinese] Available from: http://d.old.wanfangdata.com.cn/ Periodical/zhyxcszz201703010

[34] Teixeira SR, Dalto VF, Maranho DA, Zoghbi-Neto OS, Volpon JB, Nogueira-Barbosa MH. Comparison between Graf method and pubo-femoral distance in neutral and flexion positions to diagnose developmental dysplasia of the hip. Eur J Radiol 2015;84:301-306.

[35] Tréguier C, Chapuis M, Branger B, Bruneau B, Grellier A, Chouklati $\mathrm{K}$, et al. Pubo-femoral distance: an easy sonographic screening test to avoid late diagnosis of developmental dysplasia of the hip. Eur Radiol 2013;23:836-844. 